\title{
Predictors of preventive behavior of nosocomial infections in nursing staff: a structural equation model based on the social cognitive theory
}

Seyed-Mousa Mahdizadeh ${ }^{1,2}$, Seyedeh Belin Tavakoly Sany ${ }^{3,4}$, Davood Robat Sarpooshi ${ }^{5}$, Alireza Jafari ${ }^{6}$ and Mehrsadat Mahdizadeh ${ }^{3,4^{*}}$

\begin{abstract}
Background: The occurrence of nosocomial infections remains a health threat to patients and hospital staff. This study applied social-cognitive theory for predicting determinants of nosocomial infections control behaviors in hospital nursing Staff.

Methods: In this cross-sectional study, 280 nurses and assistant nurses were selected by random sampling from intensive care wards including CCU, ICU, NICU, dialysis of educational hospitals in Mashhad, Iran in 2020. Data were collected using a 5-point Likert scale structural questionnaire based on social cognitive theory constructs. Using the structural equation modeling method, direct and indirect relationships of social cognitive factors on preventive behaviors of nosocomial infections were analyzed via AMOS 23.0.

Results: Our results showed that self-regulation, outcome expectations, and barrier constructs had a direct effect on behavior and the highest effect was related to self-regulation structure $(p<0.001)$. The constructs of social support, modeling, perceived environment and Task self-efficacy had an indirect effect on behavior and the most impact was related to the constructs of perceived environment $(p<0.05)$.

Conclusion: Considering that self-regulation, outcome expectation and barriers have a significant effect on following the preventive behaviors of nosocomial infections in nursing staff. It is suggested that policymakers and planners try to reduce barriers, strengthen behavioral motivation, and empower nursing staff by teaching selfregulatory strategies.
\end{abstract}

Keywords: Nosocomial infections, Hospital, Nurse, Social cognitive theory, Structural equation modeling

\footnotetext{
* Correspondence: mahdizadehtm@mums.ac.ir

${ }^{3}$ Department of Health Education and Health Promotion, Faculty of Health,

Mashhad University of Medical Sciences, Mashhad, Iran

${ }^{4}$ Social Determinants of Health Research Center, Mashhad University of

Medical Sciences, Mashhad, Iran

Full list of author information is available at the end of the article
}

C C The Author(s). 2021 Open Access This article is licensed under a Creative Commons Attribution 4.0 International License, which permits use, sharing, adaptation, distribution and reproduction in any medium or format, as long as you give appropriate credit to the original author(s) and the source, provide a link to the Creative Commons licence, and indicate if changes were made. The images or other third party material in this article are included in the article's Creative Commons licence, unless indicated otherwise in a credit line to the material. If material is not included in the article's Creative Commons licence and your intended use is not permitted by statutory regulation or exceeds the permitted use, you will need to obtain permission directly from the copyright holder. To view a copy of this licence, visit http://creativecommons.org/licenses/by/4.0/ The Creative Commons Public Domain Dedication waiver (http://creativecommons.org/publicdomain/zero/1.0/) applies to the data made available in this article, unless otherwise stated in a credit line to the data. 


\section{Background}

Although the quality of health services has been improved and infection prevention and control methods have been developed, the occurrence of nosocomial infections remains a health threat to patients and hospital staff [1]. Due to the biological characteristics of nosocomial infection pathogens, such as antibiotic resistance and high pathogenicity, as well as the sensitivity and frailty of hospitalized patients, there is a strong relationship between nosocomial infection and mortality [2].

Nosocomial infections affect many patients around the world. Roughly, 15\% of hospitalized patients suffer from these infections. The economic losses from these infections are increasing. The incidence rate in developed countries is about 3.5 to $12 \%$. The prevalence of these infections in underdeveloped countries is about three times higher than in developed countries [3]. In these countries, this rate varies between 5.7-19.1\% [4]. In Iran, most of these infections occur in intensive care units and surgical wards [5]. Giving the role and duties of clinical staff in hospitals, they can be a factor in the transmission of nosocomial infections. Adherence to infection control instructions such as the use of masks and cleaning and disinfection of hands and equipment after contact with patients and their contaminated equipment is the most important duties of these employees. Therefore, adherence to these behaviors can reduce nosocomial infections [3].

To prevent and control nosocomial infections, it is essential to determine the predictors of preventive behaviors of nosocomial infection. For this end, effective models are needed to improve patient safety and reduce nosocomial infections [6]. Social cognitive theory is a comprehensive theory. According to this theory, behavior is formed from the interaction of environmental, personal and behavioral factors [7]. Self-regulation, selfefficacy, outcome expectation, and environment are important constructs of social cognitive theory $[8,9]$. These constructs can be used as a guide for developing procedures and implementing of interventions to change healthy behaviors. Bandura emphasized that self-regulation strategies (i.e., ability to self-monitor and evaluate their behavior) must be used to set goals and plan to adopt and maintain a behavior [8]. Selfmonitoring is a guide to evaluating one's progress toward goals, which leads one to a behavior [10]. The results of the study indicated that self-regulation is one of the determinants of behavior related to standard precautions such as hand hygiene [11].

A study showed that nurses in the intensive care unit need to strengthen self-efficacy as one of the internal factors in order to carry out infection control-related behaviors [12]. Another study also showed that selfefficacy is related to nursing care [13].
In previous studies, the effect of social cognitive factors on hand hygiene as one of the measures in the control and prevention of nosocomial infections has been investigated, but the effect of social cognitive factors on compliance with standard precautions for nosocomial infection control is not well understood. In a study that was conducted to identify social cognitive factors affecting on hand hygiene in hospital nurses, subjective norms, attitudes, perceived behavioral control, risk perception and intention were identified as important predictors of hand hygiene [14]. Structural equation modeling helps researchers determine how the theory works to influence the outcome because it approaches the model through predictor variables, the mediation, and the consequence of the variables' relationships with each other [15]. It is used for testing several theoretical models, which define the structure of constructs and their relationship with each other [16-19].

This study aimed to provide Structural equation model to predict social cognitive theory on behaviors related to prevent and control of nosocomial infections in nursing staff.

\section{Methods}

Study design, setting and participant requirement

This study used a cross-sectional, self-reported design in evaluating the predictors of behaviors related to prevent and control nosocomial infections among nursing staff. Data were collected from August to December 2020. A convenience sample of 280 nursing staff were selected for the study. The research sample was selected from the nursing staff (nurse and assistant nurses) working in the intensive care units including CCU, ICU, NICU, dialysis units in academic hospitals in Mashhad, Iran. Inclusion criteria were willingness to participate in the study, employment in intensive care units for more than 6 months. Exclusion criteria was incomplete of the questionnaire by study participants.

\section{Questionnaire}

This study used a self-report questionnaire to collect data. This questionnaire included 2 part; part 1 included demographic characteristics (e.g., age, gender, educational status, training about nosocomial infections and job). Part 2 elicited constructs of social cognitive theory including perceived barriers, task self-efficacy, selfregulation, outcome expectations, perceived environment, modeling, social support, and behaviors related to prevent and control of nosocomial infections. This part of questionnaire included 36 items (perceived barriers 5 items, task self-efficacy 4 items, self-regulation 5 items, outcome expectations 4 items, perceived environment 2 items, modeling 3 items, social support 3 items, and practices of nosocomial infection control 10 items). Each 
item in this section were scored from 1 to 5 on a Likert scale from completely disagreement to completely agreement.

The content validity methods were used to assess the validity of the questionnaire. For this purpose, the opinions of 10 experts in health education, nursing, and infection control on the items of the questionnaire were received and the items were modified or deleted based on their suggestions. Content Validity Index (CVI) and Content Validity ratio (CVR) assessed for each items of structures (self-efficacy, modeling, social support, selfregulation, perceived environment, perceived barriers, outcome expectation, and behaviors). The CVR value for the items was between 0.76 and 0.91 . Also, the CVI value for the items was between 0.81 and 0.98 . The reliability of the instrument was evaluated using test-retest method and Cronbach's alpha test. For external reliability, 30 nurses and assistant nurses completed the questionnaires twice with an interval of 10 days, except for the study sample, and the data were analyzed by Pearson correlation coefficient. Cronbach's alpha test was also used to assess internal validity (Table 1).

\section{Statistical analyses}

The collected data were analyzed using IBM SPSS Statistics 21.0 (IBM Corp., Armonk, NY) for evaluating the normality of variables and descripting of statistics. In this study, the principles of social cognitive theory were used to structural equation modeling. The basic conceptual model of behavior predictors based on social cognitive theory [20], which provides a theoretical framework for our study, is illustrated in Fig. 1. The fit of the constructs of social cognitive theory for behaviors related to the control of nosocomial infections in hospital nursing staff was examined using the latent variable structural equation model (SEM) with AMOS software version 24.

Structural equation modeling is a detailed statistical method for testing models that contain both causal relationship and correlations between observed variable and

Table 1 The results of reliability tool based for the constructs of social cognitive theory

\begin{tabular}{lll}
\hline Subscale & Cronbach's alpha & Test-re test \\
\hline Perceived barriers & 0.832 & 0,810 \\
Perceived environment & 0.628 & 0,870 \\
Self-regulation & 0.859 & 0,892 \\
Outcome expectations & 0.842 & 0,861 \\
Self-efficacy & 0.830 & 0,924 \\
Social support & 0.803 & 0,893 \\
Modeling & 0.730 & 0.792 \\
Behavior & 0.933 & 0,911 \\
All constructs & 0.816 & 0.781 \\
\hline
\end{tabular}

latent variables. SEM is used in social and behavioral sciences, education, biology, economy, marketing and medicine, which is based on substantial or suggested theories that describe and explain phenomena under investigation. We used R2 and the path coefficients to test the fit of the model. Before carrying out the SEM analysis, the normality of variables was examined [21]. All the indicators in the model were treated as reflective indicators of their respective constructs. We developed the model (theoretically driven) with eight latent factors. The modification index suggested correlation of several error terms. After covering the errors, we obtained the acceptable model fit. The goodness-of-fit of the model was confirmed using the $\chi^{2}$ statistic, RMSEA (RootMean-Square Error of Approximation), CFI (Comparative Fit index), IFI (Incremental Fit Index), PNFI (Parsimonious Normal Fit Index), and PGFI (Parsimonious Good Fit Index) [15]. Parameter estimation and effect analysis were performed using the bootstrapping method. Statistical significance was set at $P<0.05$.

\section{Ethics approval and consent to participate}

This study was conducted in accordance with the principles of Declaration of Helsinki. All methods were carried out in accordance with relevant regulations and guidelines. This study is based on a research study approved by the ethics committee of Mashhad University of Medical Sciences with the ethical code IR.MUMS.REC.1398.005. Informed written consent was obtained from all participants before start of this study. By completing consent form, participants were informed about the purpose and method of the study. Participants were also informed that the researchers are committed to answering their questions and that their information was kept confidential. In addition, participants were aware that their participation in the study was voluntary and that they could leave the study at any time.

\section{Results}

Participants had a mean of age $35.42 \pm 8.06$ years. Fiftysix percent of participants in this sample were men, and most of the samples had a bachelor's degree. Eighty percent of the samples participated in an infection controltraining course (Table 2).

Before performing the structural equation model, first, the remote points and the normality of the variables were examined. The remote points were checked with the help of the value of mahalanobis distance of each observation and if necessary, they were removed. In the study of critical ratios of skewness or elongation of variables, the normality of multivariate was confirmed, therefore, the maximum likelihood method was used to estimate the parameters. Then, the structural equation model of social cognitive theory constructs was examined 


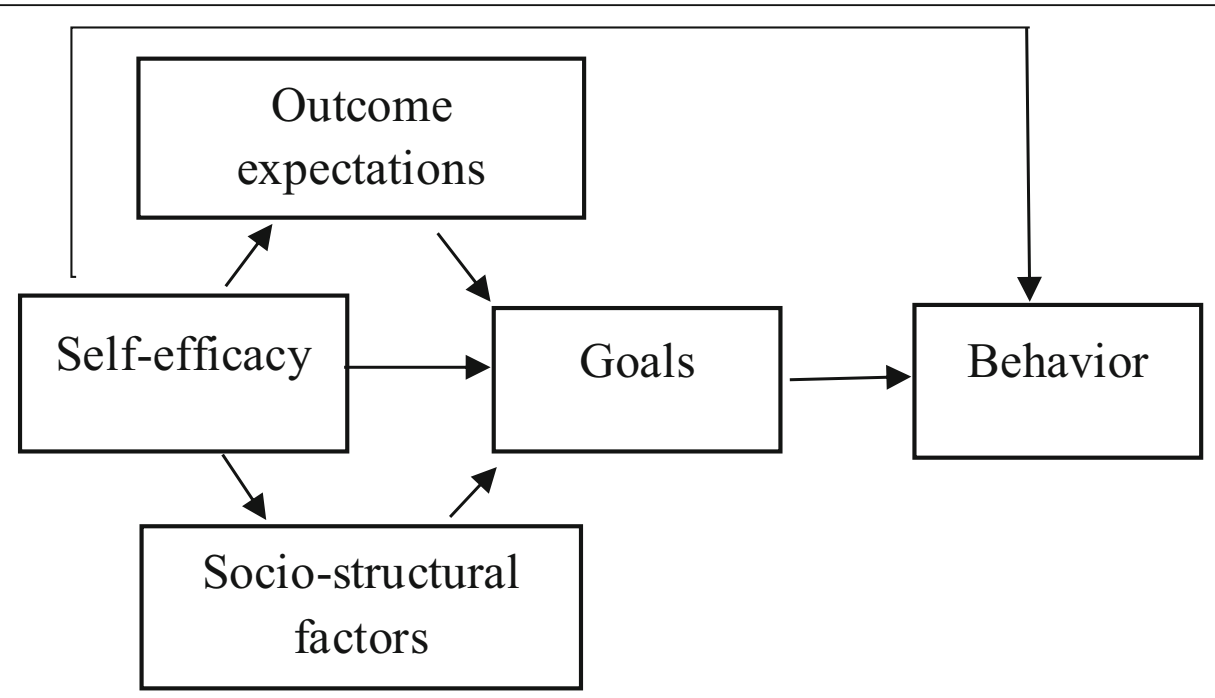

Fig. 1 Theoretical model of Social cognitive theory

and analyzed. Based on the results of the indicators, the desired model has been accepted) $\mathrm{X}^{2}=1184.739(p>$ 0.05), $\mathrm{df}=572, \mathrm{X}^{2} / \mathrm{df}=2.07, \mathrm{CFI}=0.910$, RMSEA $=0.062$, PNFI $=0.739$, and PGFI $=0.811$ IFI $=0.910, p<0.001)$.

The total effect size of social support on perceived environment was 0.502 , perceived environment on task self-efficacy 0.264 , social support on task self-efficacy 0.550 , outcome expectations on self-regulation 0.729 , task self-efficacy on self-regulation 0.140 , perceived environment on self-regulation 0.037 , self-regulation and outcome expectations and barrier on behavior Respectively $0.490 / 0,0.780,-0.211$. Most of the direct and indirect causal effects were statistically significant and positive. Most of the direct and indirect causal effects were statistically positive and significant (Table 3 ).

The constructs of barriers, perceived environment, outcome expectations, task self-efficacy, social support, and modeling were able to predict $70 \%$ of the variance of Self-regulation construct. The variance of the structures of this model in predicting the variance of the structure of behavior are shown in Fig. 2.

The results of the structural equation model showed that self-regulation, outcome expectations, and barrier constructs had a direct effect on behavior and the highest effect was related to self-regulation structure. Also, Percentage of total direct effects of structures are greater than the total indirect effects of structures. The structures of social support, modeling, perceived environment and task self-efficacy had an indirect effect on behavior and the greatest effect was related to perceived environmental structures (Table 3).

\section{Discussion}

In this study, the role of social cognitive theory constructs as predictive factors of behavior related to the control and prevention of nosocomial infections in hospital nursing staff was evaluated. Structural equation analysis shows that the theoretical model is suitable for

Table 2 General Characteristics of Participants

\begin{tabular}{llll}
\hline Variables & & N & \% \\
\hline Gender & Male & 157 & 123 \\
& Female & 84.1 & 43.9 \\
Educational status & Diploma and lower & 181 & 29.6 \\
& Bachelor's degree & 15 & 65.0 \\
Infection control training course & Master's degree and higher & 223 & 5.4 \\
& Yes & 50.3 & 19.7 \\
Job & No & 57 & 149 \\
& Assistant nurse & 131 & 48.52 \\
\hline
\end{tabular}


Table 3 Direct and indirect effects of constructs social cognitive theory

\begin{tabular}{|c|c|c|c|}
\hline \multirow[t]{2}{*}{ Predictors } & \multicolumn{3}{|c|}{ Causal Effect } \\
\hline & Direct & Indirect & Total effects \\
\hline Social support $\rightarrow$ Environment & $0.502^{*}$ & - & 0.502 \\
\hline Social support $\rightarrow$ Modeling & $0.686^{*}$ & - & 0.686 \\
\hline Environment Perception $\rightarrow$ Task self-efficacy & $0.264^{*}$ & - & 0.264 \\
\hline Social support $\rightarrow$ Task self-efficacy & $0.417^{*}$ & $0.133^{* *}$ & 0.550 \\
\hline Modeling $\rightarrow$ Outcome expectations & $0.563^{*}$ & - & 0.563 \\
\hline Environment Perception $\rightarrow$ Barrier & $-0.980^{*}$ & - & -0.980 \\
\hline Outcome expectations $\rightarrow$ Self-regulation & $0.729^{*}$ & - & 0.729 \\
\hline Social support $\rightarrow$ Self-regulation & $0.129^{* *}$ & $0.358^{* *}$ & 0.487 \\
\hline Task self-efficacy $\rightarrow$ Self-regulation & $0.140^{* *}$ & - & 0.140 \\
\hline Social support $\rightarrow$ Outcome expectations & - & $0.386^{* *}$ & 0.386 \\
\hline Social support $\rightarrow$ Barrier & - & $-0.492^{* *}$ & -0.492 \\
\hline Modeling $\rightarrow$ Self-regulation & - & $0.411^{* *}$ & 0.411 \\
\hline Environment Perception $\rightarrow$ Self-regulation & - & $0.037^{* *}$ & 0.037 \\
\hline Self-regulation $\rightarrow$ Behavior & $0.490^{*}$ & - & 0.490 \\
\hline Outcome expectations $\rightarrow$ Behavior & $0.423^{* *}$ & $0.357^{* *}$ & 0.780 \\
\hline Barrier $\rightarrow$ Behavior & $-0.211^{* *}$ & - & -0.211 \\
\hline Social support $\rightarrow$ Behavior & - & $0.179^{* *}$ & 0.179 \\
\hline Modeling $\rightarrow$ Behavior & - & -0.037 & -0.037 \\
\hline Environment Perception $\rightarrow$ Behavior & - & $0.225^{* *}$ & 0.225 \\
\hline Task self-efficacy $\rightarrow$ Behavior & - & $0.068^{* *}$ & 0.068 \\
\hline Through total causal effect & 2.729 & 1.625 & 4.354 \\
\hline Percentage of direct and indirect effects & $\begin{array}{l}2.729 / 4.354 \\
=62.68 \%\end{array}$ & $\begin{array}{l}1.625 / 4.354 \\
=37.32 \%\end{array}$ & \\
\hline
\end{tabular}

${ }^{*} P<0.001,{ }^{* *} P<0.05$

the data and explains the nosocomial infections control behavior in the hospital nursing staff. In the test of goodness-of-fit of the final modified model, the absolute fit indices ( $\mathrm{X} 2$, and RMSEA), the comparative fit indices (IFI and CFI) and parsimonious fit indices (PCFI and PNFI) met the criteria, indicating that the model-fit well with the data. The literature described that a good model is with insignificant $\chi^{2}(p \geq 0.05)$, IFI $\geq 0.90$, PGFI $\geq 0.50$, RMSEA $\leq 0.08$, PNFI $\geq 0.50$, and CFI $\geq 0.90$ [22-24].

Our research results show that self-regulation directly plays an important role in the performance of hospital nursing in controlling and preventing nosocomial infections. Consistent with these results, a study showed that the process of self-regulatory is an important predictor of hand hygiene [25]. In fact, when individuals control their performance, they are more likely to set more realistic and challenging goals, thereby helping to overcome behavioral barriers [26].

In this study, the results show that independent of self-regulatory behaviors, self-efficacy has little effect on behaviors. Consistent with our results, studies have shown that one of the determinants of healthy behavior is self-efficacy, which can predict various healthy behaviors, including prevention of nosocomial infections and hand hygiene $[27,28]$. Although self-efficacy is often a powerful predictor of behavioral adoption and maintenance in healthy behaviors, a meta-analysis showed that self-efficacy has different effects on healthy behaviors are [29]. Researchers also describe people who have a high level of self-efficacy trying harder to achieve their goals when faced with obstacles [30].

In the present study, outcome expectation is influenced by modeling, and directly and indirectly affects the behavior of nursing staff through self-regulation. Other researchers have also shown that observational learning can enhance outcome expectations and can influence behavior [31]. Contrary to these results, in another study that showed the results of predicting the constructs of protection motivation theory integrated with the outcome expectation construct of the social cognitive theory related to protective measures against Ebola infection, the outcome expectation construct did not predict the protective behaviors of nurses against Ebola infection [32]. 




The results of this study indicate that the perceived environment affects barriers. Barriers also have a direct and negative effect on the preventive behavior of nosocomial infections in hospital nurses. Consistent with these results, other studies have shown that barriers such as insufficient knowledge, personal attitude and judgment, environmental constraints, and insufficient leadership skills have a negative effect on nurses' adherence to standard precautions [33-36].

In this study, social support is another determinant of nosocomial infections prevention behavior, which indirectly affects it. The influence of social support on preventive behaviors of nosocomial infections was through self-regulation, self-efficacy, perceived environment and modeling. Based on these results, the literature describes that self-efficacy and social support are important facilitator of self-regulation, especially planning [37]. In another studies, social support, including institutional and management support for stablishing a safe environment and providing facilities, had a significant impact on compliance with standard precautions (such as hand hygiene) [38-40].
Our results showed that modeling has a negative effect on the preventive behavior of nosocomial infections in hospital nursing staff. This factor also had an indirect effect on behavior through barriers. The literature points out that the role of a mentors as a role model affects the hand hygiene behavior of nursing students [41]. In another study, the lack of appropriate role models was identified as one of the problems of non-compliance with standard perceptive measures, which was caused by environmental factors and barriers (including conflicts between professional, unsupported organizational culture and financial issues [42].

In the present study, perceived environment had an indirect effect on the preventive behavior of nosocomial infections in the hospital nursing staff through barriers. Consistent with these results, earlier studies have shown that environment factors (for example, lake of access to personal protective equipment, heavy workload, and crowded ward) can have a significant impact on compliance with standard precautions by healthcare staff $[43,44]$. 


\section{Limitations and future research}

This study tested the predictive effect of social cognitive theory constructs on a set of behaviors preventing nosocomial infections. While, previous studies have examined factors related to hand hygiene behavior. This study was conducted in all intensive care units in several hospitals, therefore, the generalized findings are appropriate. One of the weaknesses of the study is that the effect of knowledge and demographic factors such as age, gender and education, which have been identified in previous studies as important factors on adherence to preventive behaviors of nosocomial infections, was not examined. This study was also conducted in teaching hospitals that have special conditions in the hospitalization, treatment and nursing-care processes, and therefore it is necessary to examine the interaction of environmental, personal and behavioral factors in other non-teaching and private hospitals.

\section{Conclusion}

The present study demonstrates that self-regulation, outcome expectations, and barriers have a significant impact on adherence to preventive behavior of nosocomial infections in nursing staff. In addition, current analyzes shows that although self-efficacy is an important precursor to self-regulation, social support was even a stronger predictor. The social support indirectly affected selfregulation through self-efficacy. In addition, social support directly led participants to use self-regulation strategies, and therefore, more compliance with prevention behaviors of nosocomial infections. It is suggested that policy makers and planners try to reduce barriers, strengthen behavioral motivation, and empower nursing staff by teaching self-regulatory strategies such as goal setting, self-monitoring, and planning to promote behaviors that prevent nosocomial infections. In addition, it is recommended that future behavioral psychology models be used in future studies to test the relationship between other variables and preventive behavior of nosocomial infections in other health care providers and nongovernmental hospitals.

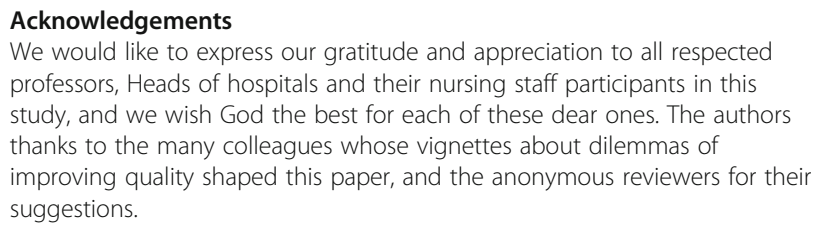

\section{Authors' contributions}

In this study, SM. M involved in the data collection. AJ and SB.TS analyzed and interpreted the data. M. M and D.RS drafted the manuscript. SM. M and M. M designed and implemented of the project. All authors read and approved final manuscript.

\section{Funding}

The Mashhad University of Medical Sciences funded this project.
Availability of data and materials

Data and materials can be requested from the corresponding author.

\section{Declarations}

\section{Ethics approval and consent to participate}

This study was conducted in accordance with the principles of Declaration of Helsinki. All methods were carried out in accordance with relevant regulations and guidelines. This study is based on a research study approved by the ethics committee of Mashhad University of Medical Sciences with the ethical code IR.MUMS.REC.1398.005. Informed written consent was obtained from all participants before start of this study. By completing consent form, participants were informed about the purpose and method of the study. Participants were also informed that the researchers are committed to answering their questions and that their information was kept confidential. In addition, participants were aware that their participation in the study was voluntary and that they could leave the study at any time.

\section{Consent for publication}

Not applicable.

\section{Competing interests}

The author(s) declare that they have no competing interests.

\section{Author details}

${ }^{1}$ Department of Medical-Surgical Nursing, School of Nursing and Midwifery, Mashhad University of Medical Sciences, Mashhad, Iran. ${ }^{2}$ Nursing and Midwifery Care Research Center, Mashhad University of Medical Sciences, Mashhad, Iran. ${ }^{3}$ Department of Health Education and Health Promotion, Faculty of Health, Mashhad University of Medical Sciences, Mashhad, Iran. ${ }^{4}$ Social Determinants of Health Research Center, Mashhad University of Medical Sciences, Mashhad, Iran. ${ }^{5}$ School of health, Sabzevar University of Medical Sciences, Sbzevar, Iran. ${ }^{6}$ Department of Health Education and Health Promotion, School of Health, Social Development and Health Promotion Research Center, Gonabad University of Medical Sciences, Gonabad, Iran.

Received: 19 December 2020 Accepted: 22 October 2021

Published online: 31 October 2021

\section{References}

1. Eybpoosh S, Eshrati B. Nosocomial infection surveillance system in Iran: structures, processes and achievements. Iran J Epidemiol. 2019;15(1):105-15.

2. Kritsotakis El, Kontopidou F, Astrinaki E, Roumbelaki M, loannidou E, Gikas A. Prevalence, incidence burden, and clinical impact of healthcare-associated infections and antimicrobial resistance: a national prevalent cohort study in acute care hospitals in Greece. Infect Drug Resist. 2017;10:317.

3. Khan HA, Baig FK, Mehboob R. Nosocomial infections: epidemiology, prevention, control and surveillance. Asian Pac J Trop Biomed. 2017;7(5): 478-82.

4. Haque M, McKimm J, Sartelli M, Dhingra S, Labricciosa FM, Islam S, et al. Strategies to prevent healthcare-associated infections: a narrative overview. Risk Management Healthcare Policy. 2020;13:1765.

5. Esfandiari A, Salari H, Rashidian A, Asl HM, Foroushani AR, Sari AA. Eliminating healthcare-associated infections in Iran: a qualitative study to explore stakeholders' views. Int J Health Policy Manag. 2018;7(1):27.

6. Michinov E, Buffet-Bataillon S, Chudy C, Constant A, Merle V, Astagneau P. Sociocognitive determinants of self-reported compliance with standard precautions: development and preliminary testing of a questionnaire with French health care workers. Am J Infect Control. 2016;44(1):14-9.

7. Bandura A. Health promotion by social cognitive means. Health Educ Behav. 2004;31(2):143-64.

8. Bandura A. The primacy of self-regulation in health promotion. Appl Psychol. 2005;54(2):245-54.

9. Bandura A. Human agency in social cognitive theory. Am Psychol. 1989; 44(9):1175.

10. Bandura A. Self-regulation of motivation and action through goal systems. In: Cognitive perspectives on emotion and motivation: Springer; 1988. p. 37-61.

11. Gaube S, Fischer P, Lermer E. Hand (y) hygiene insights: applying three theoretical models to investigate hospital patients' and visitors' hand hygiene behavior; 2020. 
12. Kurnia TA, Trisyani $Y$, Prawesti A. Factors associated with nurses' self-efficacy in applying palliative care in intensive care unit. Jurnal Ners. 2018;13(2):219-26.

13. Zahroh R, Qomariah SN, Ningsih SU, Bakar A. Self Efficacy Associated with Nurse Caring Behavior in Nursing Services in Private Hospitals. Int J Psychosoc Rehabil. 2020;24(09):2710-4.

14. White KM, Starfelt LC, Jimmieson NL, Campbell M, Graves N, Barnett AG, et al. Understanding the determinants of Australian hospital nurses' hand hygiene decisions following the implementation of a national hand hygiene initiative. Health Educ Res. 2015;30(6):959-70.

15. Shaheen F, Ahmad N, Waqas M, Waheed A, Faroog O. Structural equation modeling (SEM) in social sciences \& medical research: a guide for improved analysis. Int J Acad Res Business Soc Sci. 2017;7(5):132-43.

16. Graffigna $G$, Barello S, Bonanomi A. The role of patient health engagement model (PHE-model) in affecting patient activation and medication adherence: a structural equation model. PLoS One. 2017;12(6):e0179865.

17. Esmaeily H, Peyman N, Taghipour A, KHorashadizadeh F, Mahdizadeh M. A structural equation model to predict the social-cognitive determinants related to physical activity in Iranian women with diabetes mellitus. J Res Health Sci. 2014;14(4):296-302.

18. Reyes Fernández B, Knoll N, Hamilton K, Schwarzer R. Social-cognitive antecedents of hand washing: action control bridges the planningbehaviour gap. Psychol Health. 2016;31(8):993-1004.

19. Zhang C-Q, Fang R, Zhang R, Hagger MS, Hamilton K. Predicting hand washing and sleep hygiene behaviors among college students: test of an integrated social-cognition model. Int J Environ Res Public Health. 2020; 17(4):1209.

20. Conner M, Norman P. EBOOK: predicting and changing health behaviour: research and practice with social cognition models: McGraw-hill education (UK); 2015.

21. Civelek ME. Essentials of structural equation modeling. In: Essentials of Structural Equation Modeling (2018); 2018.

22. SCHREIBER JB, STAGE FK, KING J, NORA A, EA BARLOW. Reporting Structural Equation Modeling and Confirmatory Factor Analysis Results: A Review; 2006.

23. Schermelleh-Engel $\mathrm{K}$, Moosbrugger $\mathrm{H}$. Evaluating the fit of structural equation models: Tests of significance and descriptive goodness-of-fit measures. J Met Psychol Res. 2003;8(2):23-74.

24. Cangur S, Ercan I. Comparison of model fit indices used in structural equation modeling under multivariate normality. J Mod Appl Stat Methods. 2015;14(1):14.

25. Gaube S, Fisher P, Lemer E. Hand (y) Hygiene Insights: Applying Three Theoretical Models to Investigate Hospital Patients' and Visitors' Hand Hygiene Behavior. PloS one. 2021;16(1):e024555443.

26. Kwasnicka D, Dombrowski SU, White M, Sniehotta F. Theoretical explanations for maintenance of behaviour change: a systematic review of behaviour theories. Health Psychol Rev. 2016;10(3):277-96.

27. Winslow S, DeGuzman P, Kulbok P, Jackson S. Nurses' self-efficacy and academic degree advancement. J Nurses Prof Dev. 2014;30(3):110-6.

28. von Lengerke T, Lutze B, Graf K, Krauth C, Lange $K$, Schwadtke L, et al. Psychosocial determinants of self-reported hand hygiene behaviour: a survey comparing physicians and nurses in intensive care units. J Hosp Infect. 2015;91(1):59-67.

29. Zhang C-Q, Zhang R, Schwarzer R, Hagger MS. A meta-analysis of the health action process approach. Health Psychol. 2019;38(7):623.

30. Lhakhang P, Lippke S, Knoll N, Schwarzer R. Evaluating brief motivationa and self-regulatory hand hygiene interventions: a cross-over longitudinal design. BMC Public Health. 2015;15(1):1-9.

31. Crosby R, Salazar L, DiCelemente R. Social cognitive theory applied to health behavior. In: Gartside M, Burlington MA, Jones, Bartlett Learning, editors. Health Behavior Theory for Public Health: Principles, Foundations, and Applications; 2013. p. 163-86.

32. Leigh L, Taylor C, Glassman T, Thompson A, Sheu J-J. A Cross-Sectional Examination on the Factors Related to Emergency Nurses' Motivation to Protect Themselves against an Ebola Infection. J Emerg Nurs. 2020;48(6):81426.

33. Pranita D, Mediawati AS, Mirwanti R. Perceived Barriers toward Standard Precautions Implementations among Nurses in the Emergency Department. J Nurs Care. 2019:2(3):178-192.

34. Rosenberg A. Hand Hygiene Barriers faced byHealth Care Workers in The Gambia:: A Health Belief Model Approach; 2016.
35. Garbuja CK, Samikshya K, Rana MS. Perceived barriers to adherence to standard precautions among healthcare personnel working in a teaching Hospital of Palpa District, Nepal. J Lumbini Med Coll. 2019;7(2):100-6.

36. Cheung K, Chan CK, Chang MY, Chu PH, Fung WF, Kwan KC, et al. Predictors for compliance of standard precautions among nursing students. Am J Infect Control. 2015;43(7):729-34.

37. Bandura A, Freeman W, Lightsey R. Self-efficacy: the exercise of control: Springer; 1999.

38. Oh E, Choi JS. Factors influencing the adherence of nurses to standard precautions in South Korea hospital settings. Am J Infect Control. 2019; 47(11):1346-51.

39. Kim H, Hwang YH. Factors contributing to clinical nurse compliance with infection prevention and control practices: a cross-sectional study. Nurs Health Sci. 2020;22(1):126-33.

40. Bernard L, Biron A, Lavigne G, Frechette J, Bernard A, Mitchell J, et al. An exploratory study of safety culture, biological risk management and hand hygiene of healthcare professionals. J Adv Nurs. 2018;74(4):827.

41. Labrague LJ, Rosales RA, Tizon MM. Knowledge of and Compliance with Standard Precautions among Student Nurses.

42. Hedayati $\mathrm{H}$, Marjadi B, Askarian M. Barriers to standard precautions adherence in a dental school in Iran: a qualitative study. Am J Infect Control. 2014:42(7):750-4.

43. Carter EJ, Wyer P, Giglio J, Jia H, Nelson G, Kauari VE, et al. Environmental factors and their association with emergency department hand hygiene compliance: an observational study. BMJ Qual Saf. 2016;25(5):372-8.

44. Leigh L. Behavioral and environmental attributes of Ebola epidemic in West Africa and United States emergency nurses' motivation to protect themselves against Ebola infection: University of Toledo; 2016.

\section{Publisher's Note}

Springer Nature remains neutral with regard to jurisdictional claims in published maps and institutional affiliations.

Ready to submit your research? Choose BMC and benefit from:

- fast, convenient online submission

- thorough peer review by experienced researchers in your field

- rapid publication on acceptance

- support for research data, including large and complex data types

- gold Open Access which fosters wider collaboration and increased citations

- maximum visibility for your research: over $100 \mathrm{M}$ website views per year

At $\mathrm{BMC}$, research is always in progress.

Learn more biomedcentral.com/submissions 